Divisão de Nutrição e Dietética do Instituto Central do Hospital das Clínicas da Faculdade de Medicina da USP

\title{
Implantação da educação nutricional e alimentar em pacientes de risco
}

Autores: Zambone MA', Trecco SMLS ${ }^{2}$, Evazian $\mathrm{D}^{3}$

1. Nutricionista, 2. Nutricionista Chefe 3. Nutricionista Diretora da Divisão 


\section{INTRODUÇÃO}

A Política Nacional de alimentação e Nutrição (PNAN) apresenta como propósito a melhoria das condições de alimentação, nutrição e saúde da população brasileira, mediante a promoção de práticas alimentares adequadas e saudáveis, a vigilância alimentar e nutricional, a prevenção e o cuidado integral dos agravos relacionados à alimentação e nutrição. 


\section{OBJETIVO}

Investigar em um grupo de idosos atendidos no ambulatório de nutrição, o conhecimento prévio referente ao tema alimentação saudável. 
Implantação da educação nutricional e alimentar em pacientes de risco

\section{METODOLOGIA}

$\checkmark$ Utilização do diagrama de Ishikawa - investigação da

causa

$\checkmark$ Definição um plano de ação e implementação do processo de trabalho.

$\checkmark$ Realizamos a programação do processo educativo 


\section{METODOLOGIA}

Análise de Causa $\Rightarrow$ Diagrama de Ishikawa

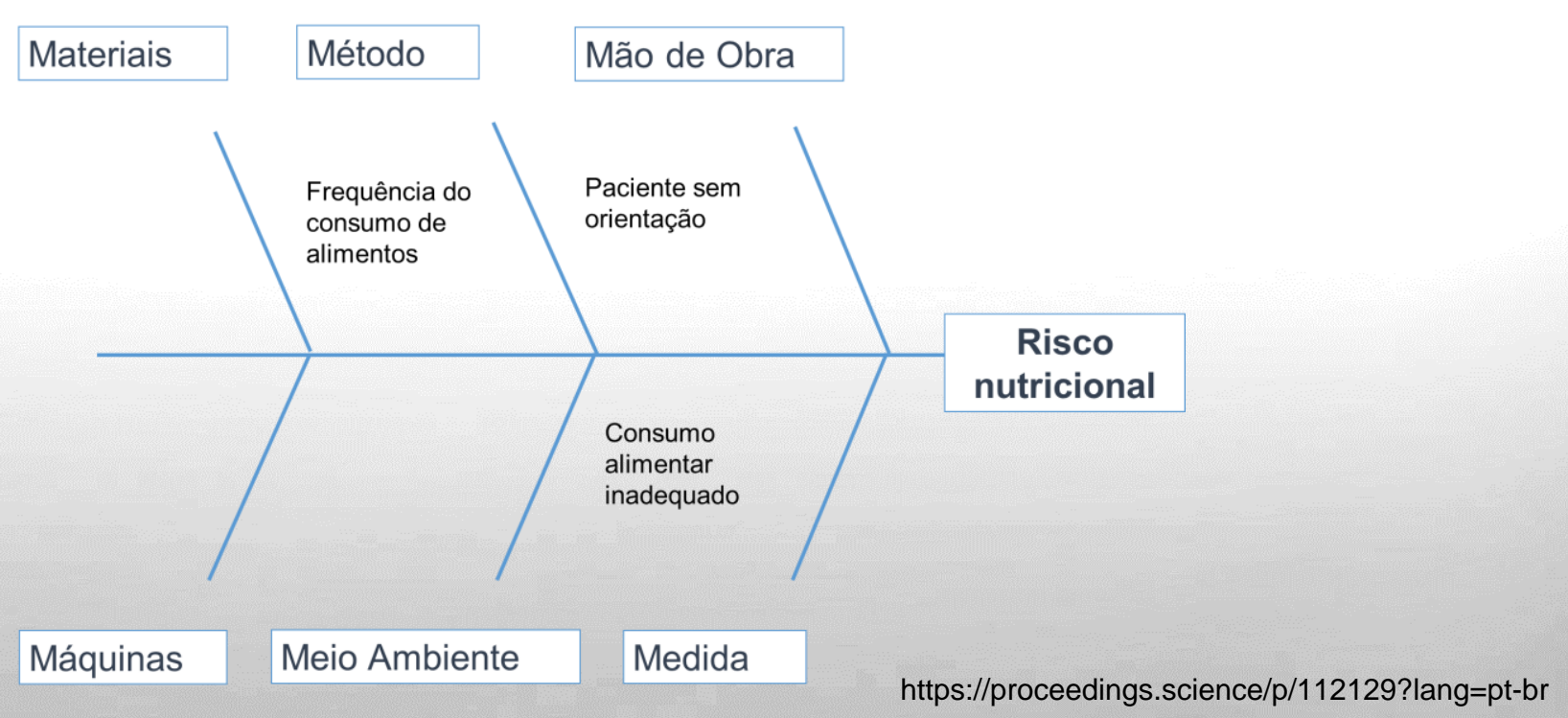


Implantação da educação nutricional e alimentar em pacientes de risco

\section{METODOLOGIA}

\section{PLANO DE AÇÃO : 5W2H}

O que será feito? Investigar o conhecimentos dos idosos sobre alimentação

Por que será feito? Para identificar risco nutricional e maus hábitos alimentares

Onde será feito? No atendimento ambulatorial para promoção a saúde

Quando será feito? No primeiro encontro do grupo de idosos e após toda programação dos encontros educativo

Quem irá fazer? Nutricionista

Como será feito? Foi aplicado questionário de conhecimento sobre alimentação proposto pelo Ministério da Saúde. 


\section{METODOLOGIA}

$\checkmark$ As atividades foram desenvolvidas na forma expositiva,

$\checkmark$ Dinâmicas de grupo, para que os participantes pudessem assimilar as informações na vida cotidiana.

$\checkmark$ Aplicação de questionário para verificar conhecimento do paciente referente a qualidade de suas refeições. 


\section{QUESTIONÁRIO}
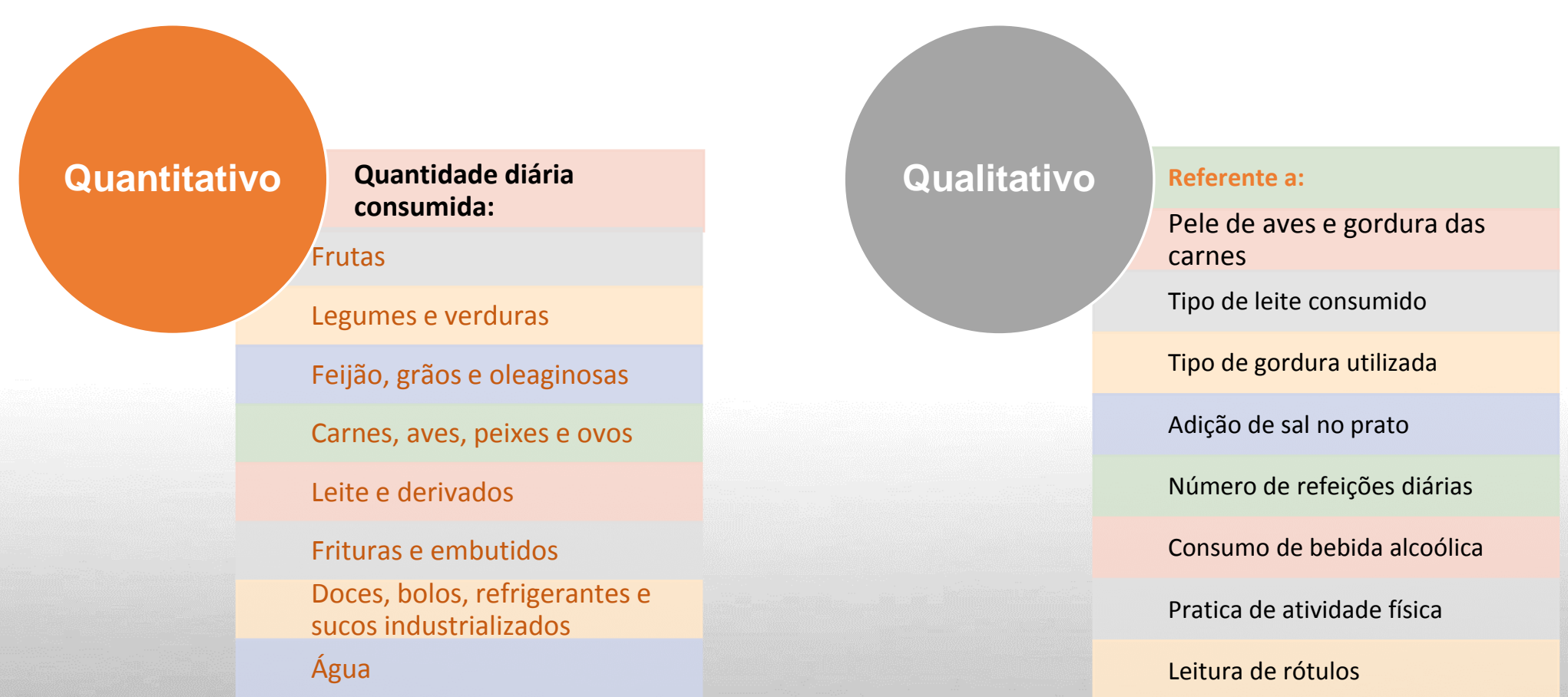


\section{RESULTADO}

Inicialmente $13 \% \square 5$ refeições /dia

Após orientação $37 \%$

Início $21 \% \longrightarrow$ Leitura dos rótulos dos alimentos

Final $43,4 \%$. 


\section{CONCLUSÃO}

Os participantes adquiriram maior conhecimento referente a alimentação saudável evidenciado na mudança dos hábitos, sugerindo que o processo de educação nutricional e alimentar foi benéfico e a abordagem educativa eficaz. 


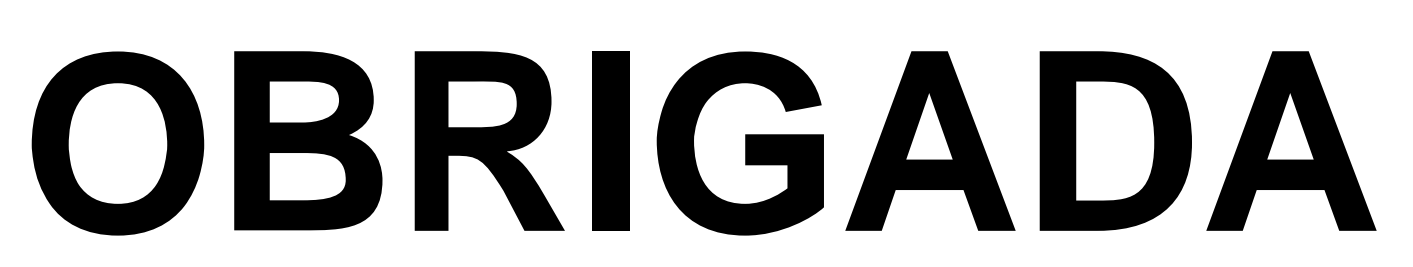

